\title{
ENFERMEDAD DIARREICA: UN PROBLEMA RECURRENTE DE SALUD PÚBLICA
}

\author{
DIARRHEAL DISEASE: A RECURRING PROBLEM IN PUBLIC HEALTH
}

\author{
Alfredo Guillén*
}

Las enfermedades diarreicas son la segunda causa de mortalidad y morbilidad en el mundo, afectan a todos los grupos etarios, pero los más afectados son los niños. En algunas zonas del Perú se ha encontrado que la incidencia de enfermedad diarreica es de 4,38 episodios por niño-año (1), siendo muy superior al promedio mundial. La enfermedad diarreica acompaña al hombre desde sus inicios y junto con las enfermedades respiratorias han sido las principales causas de morbilidad y mortalidad. La multicausalidad de la diarrea, hacía que esta enfermedad se viera como de difícil control; la aparición de nuevos agentes causantes de diarrea, sobre todo virales, aumentó esta idea, aunque probablemente se deba a que contamos con mejores métodos de detección. Por otro lado, el mejoramiento de las condiciones sanitarias ha hecho que exista una disminución de la incidencia, sobre todo en países donde estas medidas implementadas como política de salud han contando con el apoyo de decisores, administradores y trabajadores de salud. En ese contexto, cuando hablamos de diarrea, aun cuando consideramos muchos agentes microbianos, como Vibrio, Shigella, Salmonella, parásitos intestinales y virus, se debe recalcar el rol fundamental de aspectos ambientales, epidemiológicos, clínicos, terapéuticos y educacionales.

La etiología de la diarrea, en lo fundamental, no ha variado; el cambio se da en la manera en que podemos diagnosticarla. Los métodos moleculares han logrado que se pueda determinar otros agentes, como los virales. Pese a ello y a la disponibilidad de métodos como la microscopía electrónica y la utilización de pruebas rápidas que permiten el diagnóstico de rotavirus y adenovirus causantes de diarrea, no se dispone aún de pruebas utilizables por el laboratorio clínico hospitalario para agentes como los norovirus, los cuales parecen ser los agentes virales más frecuentes productores de diarrea ${ }^{(2)}$. Se requiere, por tanto, fomentar la investigación para el desarrollo de métodos simples y económicos para ampliar el diagnóstico microbiológico, siendo ello parte del trabajo que debe implementarse en el INS, los laboratorios regionales, los laboratorios de investigación de universidades y los centros de investigación.

La prevención de la diarrea es un concepto que no ha cambiado. Por ejemplo, el mejoramiento de las condiciones sanitarias como medida de salud pública es un hecho conocido desde la intervención de John Snow en la epidemia de cólera en Londres ${ }^{(3)}$ hasta lo ocurrido en el Perú después de la epidemia del cólera, donde medidas tan simples como el lavado de manos con agua y jabón lograron una reducción importante en los casos de diarrea y condicionaron incluso la disminución sustancial de algunas otras enfermedades como la fiebre tifoidea ${ }^{(4,5)}$. Esto recalca, además, la importancia del factor educacional en la prevención de la enfermedad diarreica.

Este número de la Revista, dedicado prioritariamente a las enfermedades diarreicas, tiene vinculación con dos hechos: el primero es que hace 40 años, en el Instituto Nacional de Salud, se creó el Laboratorio Nacional de Referencia de Enterobacterias dedicado a la vigilancia de bacterias enteropatógenas, con labores de diagnóstico, vigilancia, investigación y docencia, lo cual permitió el desarrollo y la estandarización de la metodología diagnóstica por los laboratorios clínicos y hospitalarios en Perú. Dentro de sus funciones realiza la vigilancia de agentes como Salmonella, Shigella, Vibrio y otros enteropatógenos; además, desarrolla investigación aplicada en colaboración con otros investigadores del sector salud, siendo reconocido como un laboratorio de referencia que ha realizado múltiples publicaciones en revistas peruanas y extranjeras. Un segundo hecho sucedió hace 20 años, cuando el cólera se presentó en nuestras costas y desde allí se extendió por todo el Perú y a otros países del continente americano. Después de 12 años, el cólera

\footnotetext{
* Editor invitado RPMESP. Médico microbiólogo. Profesor Asociado de la Facultad de Tecnología Médica Universidad Nacional Federico Villarreal. Jefe del Laboratorio de Microbiología, Clínica San Borja.

Correo electrónico: alfredo_guillen@yahoo.com
} 
desapareció; sin embargo, debemos estar vigilantes ante la epidemia de cólera que se ha presentado en Haití desde octubre de 2010 , pues ya se han notificado más de 245000 casos y 4549 defunciones a febrero de 2 011. Se ha encontrado una cepa de Vibrio cholerae con una resistencia importante a los antibióticos y que se ha desarrollado en una población con bajos recursos económicos, con mala condición sanitaria -agravada por un terremoto previo- y con un sistema de salud deficiente. Casos secundarios se han presentado en República Dominicana, Venezuela y Estados Unidos. Siempre consideraremos un riesgo de que esta enfermedad se extienda nuevamente como ocurrió en 1991, pues tenemos las condiciones climáticas y sanitarias para que esto ocurra; hoy la interrogante es si el personal de salud y el sistema sanitario están en condiciones de afrontar una nueva epidemia de cólera. Evidentemente hemos aprendido lecciones, desde el inicio de la epidemia previa, cuando el laboratorio del Instituto Nacional de Salud pudo hacer un diagnóstico rápido que permitió que se pudiera tomar medidas específicas en diagnóstico, capacitación y vigilancia. Ello incidió directamente en la implementación de medidas terapéuticas como el uso de la rehidratación oral como una medida efectiva en condiciones en las cuales el número de pacientes que se presentaban diariamente sobrepasaban largamente la capacidad de los servicios de emergencia. Entre los aportes realizados por el Perú, desde el inicio de la epidemia del cólera, podemos destacar la determinación de los serotipos que mostraban que las cepas de V. cholerae-01, sudamericana, eran similares a las aisladas en Islas Malawi (1990), Truk (1990), Tailandia (1990), Filipinas (1987) ${ }^{(6)}$; mientras en los aspectos terapéuticos, además del uso de sales de rehidratación oral, destaca la demostración de la equivalencia del uso endovenoso del cloruro de sodio al 0,9 \% como alternativa a la solución polielectrolítica recomendada en esa época ${ }^{(7)}$.

En este número, se presentan dos trabajos originales de Theresa Ochoa sobre Escherichia coli y el uso de la biología molecular para la determinación de los factores de enteropatogenicidad. En el simposio se presenta el trabajo de Jaime Martínez sobre los factores ambientales para la aparición y dispersión de epidemias de Vibrio cholerae y $V$. parahaemolyticus, discutiendo los factores importantes en la presentación de dichas epidemias y una revisión del estado actual y retos en el diagnóstico microbiológico de la diarrea. En la sección especial, destaca la contribución del Dr. Heriberto Fernández concerniente a la importancia de la infección por Campylobacter desde la perspectiva sudamericana, mientras que María Luz Zamudio presenta el uso de las nuevas tecnologías moleculares en el estudio de epidemias causadas por agentes transmitidos por alimentos como la Salmonella. Tal modelo representa la integración de los laboratorios en una red internacional que permite comprender la epidemiología de los agentes causantes de diarrea para tomar medidas de control con un adecuado soporte de laboratorio. Adicionalmente, presentamos un reporte histórico del primer aislamiento de Vibrio cholerae durante la epidemia de 1991, mientras que la sección de "Destacadas Personalidades de la Salud Pública en el Perú" está dedicada al Dr. Oscar Grados quien desarrolló los laboratorios de referencia de enteropatógenos en el INS.

Finalmente, queremos enfatizar que las intervenciones en casos de diarrea no se limitan exclusivamente al manejo antibiótico sino que implican un enfoque multidisciplinario en el cual cumplen una función primordial la educación sanitaria, la epidemiología, la salud ambiental y la intervención clínica tanto en el diagnóstico, tratamiento y prevención, siendo el desarrollo de vacunas uno de los aspectos fuertes en investigación y desarrollo.

\section{REFERENCIAS BIBLIOGRÁFICAS}

1. Kosek M, Yori PP, Pan WK, Olortegui MP, Gilman RH, Perez $\mathrm{J}$, et al. Epidemiology of highly endemic multiply antibiotic-resistant shigellosis in children in the Peruvian Amazon. Pediatrics. 2008;122:e541-549.

2. Yori PP, Schwab K, Gilman RH, Nappier s, Portocarrero DV, Black RE, et al. Norovirus highly prevalent cause of endemic acute diarrhea in children in the Peruvian amazon. Pediatr Infect Dis J. 2009,28:844 -847.

3. Cairncross S, Hunt C, Boisson S, Bostoen K, Curtis V, Fung IC, et al. Water, sanitation and hygiene for the prevention of diarrhoea. Int J Epidemiol. 2010;39(Suppl 1): i193-205.

4. Burton M, Cobb E. Donachie P, Judah G, Curtis V, Schimdt WP. The effect of handwashing with water or soap on bacterial contamination of hands. Int J Environ Res Public Health. 2011;8:97-104.

5. Curtis V, Cairncross S. Effect of washing hands with soap on diarrhea risk in the community: a systemic review. Lancet Infect Dis. 2003;3:275-281.

6. Carrillo C. El Instituto Nacional de Salud y la Epidemia de Cólera. Rev Med Hered. 1991;2(2):89-93.

7. Hinostroza J, Sovero Y, Estremadoiro L, Cieza J. Efectos de la expansión endovenosa rápida con solución Hartmann y con cloruro de sodio al $0.9 \%$, sobre el medio interno de pacientes con deshidratación severa por diarrea aguda coleriforme. Rev Med Hered. 1995;6(2):72-75. 